\title{
Downregulation of TM7SF4 inhibits cell proliferation and metastasis of A549 cells through regulating the PI3K/AKT/mTOR signaling pathway
}

\author{
XUDONG YANG ${ }^{1}$, XIAOMING SONG ${ }^{1}$, XIAOHANG WANG ${ }^{2}$, XIANGYAN LIU ${ }^{2}$ and ZHONGMIN PENG ${ }^{2}$ \\ ${ }^{1}$ Department of Thoracic Surgery, Qianfoshan Hospital, Shandong University, Jinan, Shandong 250014; \\ ${ }^{2}$ Department of Thoracic Surgery, Shandong Provincial Hospital, Shandong University, Jinan, Shandong 250021, P.R. China
}

Received April 13, 2016; Accepted March 21, 2017

DOI: $10.3892 / \mathrm{mmr} .2017 .7324$

\begin{abstract}
Lung cancer is one of the most common types of malignant tumor worldwide. The etiology of lung cancer is complex and, although significant progress has been made in previous investigations, the molecular mechanism responsible for lung cancer remains to be fully elucidated. In the present study, the association between lung cancer and transmembrane 7 superfamily member 4 (TM7SF4) was investigated. Reverse transcription-quantitative polymerase chain reaction technology was used to detect the expression of TM7SF4, and it was expressed at a high level in lung cancer. Furthermore, by overexpressing and inhibiting the expression of TM7SF4, the present study compared cell proliferation and migration rates. It was confirmed that TM7SF4 promoted lung cancer cell proliferation and migration. TM7SF4 was also confirmed to promote cancer cell migration and invasion by modulating the activation of the phosphatidylinositol 3-kinase/Akt pathway in the A549 cells. Correspondingly, the inhibition of TM7SF4 decreased the expression of proteins associated with AKT, whereas the overexpression of TM7SF4 promoted the expression of the relevant proteins. Therefore, the present study confirmed that TM7SF4 was involved in the progression of lung cancer via regulating the activation of AKT. These findings suggested that TM7SF4 may be involved in the progression of lung cancer and may be a novel therapeutic target for this disease.
\end{abstract}

\section{Introduction}

Lung cancer is a type of malignant tumor, which causes serious damage to human health (1). In previous years, the morbidity and mortality rates of lung cancer have significantly increased,

Correspondence to: Dr Zhongmin Peng, Department of Thoracic Surgery, Shandong Provincial Hospital, Shandong University, 324 Jing Wu Wei Qi Road, Jinan, Shandong 250021, P.R. China E-mail: zhongminpeng11@126.com

Key words: lung cancer, transmembrane 7 superfamily member 4, phosphatidylinositol 3-kinase/AKT/mammalian target of rapamycin, cell proliferation, cell migration and the morbidity and mortality rates of men with lung cancer are the highest among malignant tumor types, whereas among women it is the second highest $(2,3)$. Metastasis occurs readily in lung cancer and can transfer to numerous regions of the body, causing serious and life-threatening complications, leading to normal tissue destruction $(4,5)$. However, the incidence of lung cancer metastasis is relatively complex and the pathogenesis remains to be fully elucidated.

Transmembrane 7 superfamily member 4 (TM7SF4) is a type of transmembrane protein encoded by the TM7SF4 gene, which is present predominantly in dendritic cells, and is involved in biological processes, which include cell fusion, cell differentiation and immunity homeostasis $(5,6)$. It has been shown that TM7SF4 is abnormally expressed in thyroid cancer, breast cancer and several other diseases, and accumulated evidence suggests that TM7SF4 is key in a variety of prevalent types of cancer (7). In addition, TM7SF4 has a marked effect on the occurrence of tumor development, and the roles of TM7SF4 in these prevalent types of cancer have attracted significant attention, however, its role in the molecular pathogenesis underlying lung cancer remains to be elucidated $(7,8)$.

Phosphatidylinositol 3-kinase (PI3K) and AKT consist of multiple isoforms, and the PI3K/Akt pathway can regulate cellular processes as diverse as cell growth, survival, proliferation and migration $(9,10)$. PI3K/AKT has frequently been reported in investigations of signaling pathways in various types of cancer, including breast cancer, thyroid cancer, ovarian cancer and lung cancer (11-13).

The aim of the present study was to examine the correlation between the expression of TM7SF4 and cell proliferation and migration in lung cancer. Initially, the expression levels of TM7SF4 were examined and compared between the A549 lung cancer cell line and normal cell lines using reverse transcription-quantitative polymerase chain reaction (RT-qPCR) analysis. The results confirmed its high expression of TM7SF4 in lung cancer. Accordingly, the proliferation and migration of lung cancer cells, and its possible molecular mechanism were investigated. The results demonstrated that the inhibition of TM7SF4 decreased cell viability and migration, whereas the overexpression of TM7SF4 increased cell proliferation. Therefore, it was concluded that TM7SF4 promoted cell 
viability and migration. For further analysis, the signaling pathway of TM7SF4 in the regulation of lung cancer cells was investigated, and the results revealed that TM7SF4 promoted cell viability by modulating activation of the PI3K/Akt pathway in the A549 cells. Accordingly, the overexpression of TM7SF4 promoted the expression of phosphorylated ( $\mathrm{p}-\mathrm{PI} 3 \mathrm{~K}$, $\mathrm{p}$-AKT and p-mammalian target of rapamycin (mTOR). Taken together, these results provide opportunities, a theoretical basis and novel insights for further investigation and the clinical development of novel treatment strategies for lung cancer.

\section{Materials and methods}

Cell lines and cell transfection. The BEAS-2B human normal lung epithelial cell line and A549 lung cancer cell line were obtained from the American Type Culture Collection (Manassas, VA, USA). All cell lines were cultured at 5\% $\mathrm{CO}_{2}$ and at $37^{\circ} \mathrm{C}$ according to the manufacturer's protocol. The TM7SF4 overexpression and silencing vectors were constructed by Sangon Biotech Co., Ltd. (Shanghai, China). A silencing vector containing no silenced TM7SF4 sequence was transfected into the A549 cells as a control. Cell transfection was performed using Lipofectamine 2000 reagent according to the manufacturer's protocol (Invitrogen; Thermo Fisher Scientific, Inc., Waltham, MA, USA) and then incubated for various durations, including 25, 50, 75 and $100 \mathrm{~h}$.

3-(4,5-dimethylthiazol-2-yl)-2,5-diphenyltetrazolium bromide (MTT) assay. The cells were cultured on 12-well plates to a density of $5 \times 10^{4}$ cells/well. For the MTT assays, the cells were cultured on 96 -well culture plates, and seeded at $5 \times 10^{3}$ cells/well. The cells were then incubated for various durations, as stated above. Cell viability was assayed by adding $20 \mu \mathrm{l}$ of $10 \mathrm{mg} / \mathrm{ml}$ MTT (Sigma-Aldrich; Merck Millipore, Darmstadt, Germany) to $0.2 \mathrm{ml}$ of culture medium, followed by incubation for $3 \mathrm{~h}$ at $37^{\circ} \mathrm{C}$. The medium was then removed, and the MTT formazan product was dissolved in $150 \mu \mathrm{l} \mathrm{DMSO}$, followed by measuring the optical density at $590 \mathrm{~nm}$ with a Multiskan EX microplate reader (Thermo Fisher Scientific, Inc.). Three independent assays were performed (14).

Cell migration and invasion assay. Cell migration and invasion were evaluated using Transwell migration chambers (8 $\mu \mathrm{m}$ pore size; Corning Incorporated, Corning, NY, USA). The membranes for the invasion assay were coated with a diluted ECM solution (Sigma-Aldrich; Merck Millipore) and then air-dried at $4^{\circ} \mathrm{C}$. Following transfection, the cells $\left(5 \times 10^{4}\right.$ cells/well) were seeded with serum-free medium in the upper portion of a chamber. Medium containing 10\% FBS (Invitrogen; Thermo Fisher Scientific, Inc.) was added to the lower chamber, served as a chemoattractant. After 24 or $48 \mathrm{~h}$ of incubation at $37^{\circ} \mathrm{C}$, the non-invaded cells on the top of the membrane were scraped and removed using cotton swabs, whereas the invaded cells were fixed, stained with Diff-Quik and then counted using light microscopy.

RT-qPCR analysis. Total RNA was extracted from the tissue samples or cultured cells using TRIzol reagent (Takara Bio Inc., Otsu, Japan). The concentration and purity of the isolated RNA was then determined using an SMA 400 UV-VIS spectrophotometer (Merinton, Shanghai, China). Purified RNA $(0.5 \mu \mathrm{g} / \mu \mathrm{l})$ was then mixed with nuclease-free water and used for cDNA synthesis with the PrimerScript first strand cDNA synthesis kit (Invitrogen; Thermo Fisher Scientific, Inc.). The expression levels of targets in the cells were measured in an Eppendorf Mastercycler (Brinkman Instruments, Westbury, NY, USA) using the SYBR ExScriptqRT-PCR kit (Takara Biotechnology Co., Ltd., Dalian, China) at a standard final volume of $20 \mu \mathrm{l}$, which contained the following: $1.5 \mu \mathrm{l} \mathrm{cDNA}$, $10 \mu \mathrm{l}$ SYBR Premix EX Taq, $1 \mu \mathrm{l}$ of forward primer $(10 \mu \mathrm{m})$,

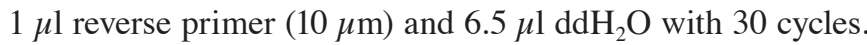
The PCR profile was run under the following cycling conditions: An initial predenaturation step at $95^{\circ} \mathrm{C}$ for $5 \mathrm{~min}$, followed by 40 cycles of denaturation at $95^{\circ} \mathrm{C}$ for $30 \mathrm{sec}$, annealing at $53^{\circ} \mathrm{C}$ for $30 \mathrm{sec}$, extension at $72^{\circ} \mathrm{C}$ for $1 \mathrm{~min}$ and a final extension at $72^{\circ} \mathrm{C}$ for $10 \mathrm{~min}$. Each reaction was performed in triplicate, and the $2^{-\Delta \Delta \mathrm{Cq}}$ method (15) was used to determine the relative gene expression levels. Melting curve analysis of the amplification products was performed at the end of each PCR to confirm that only one product was amplified and detected. Glyceraldehyde 3-phosphate dehydrogenase was selected as the internal control for mRNA or long non-coding RNAs. The primers used for target amplification are in Table I.

Western blot analysis. The cells were washed once with PBS and lysed in radioimmunoprecipitation assay buffer (Sangon Biotech Co., Ltd., Shanghai, China) containing phenylmethanesufonyl fluoride (Sigma-Aldrich; Merck Millipore), and centrifuged at $8,000 \times \mathrm{g}$ for $10 \mathrm{~min}$ at $4^{\circ} \mathrm{C}$. Supernatant was collected for the measurement of protein concentrations using a bicinchoninic acid assay kit (Pierce; Thermo Fisher Scientific, Inc.). A total of $50 \mu \mathrm{g}$ protein in each sample was boiled for $10 \mathrm{~min}$ in SDS sample buffer, separated on a $12 \%$ gel and subjected to SDS-PAGE, prior to transfer onto nitrocellulose membranes (Whatman GmbH, Dassel, Germany). Membranes were blocked in 5\% non-fat dry milk in TBST for $1 \mathrm{~h}$ at room temperature. Subsequently, membranes were incubated with the following primary antibodies: TM7SF4 (catalog no. ab96809), PI3K (catalog no. ab182651), AKT (catalog no. ab81283), mTOR (catalog no. ab87540) and GAPDH (catalog no. ab181603), at 1:1,000 dilution overnight at $4^{\circ} \mathrm{C}$. These antibodies were purchased from Abcam, Cambridge, UK. The membranes were then washed with TBST and incubated with horseradish peroxidase-conjugated goat anti-rabbit secondary antibody (catalog no. ab6721) and goat anti-mouse secondary antibody (catalog no. ab6789) (1:2,000 dilution) for $2 \mathrm{~h}$ at room temperature. Protein bands were visualized using the WEST-ZOL-plus (iNtRON Biotechnology, Seoul, Korea) western blot detection system (16). The intensity of protein bands was quantified using Image J software (version 1.46; National Institutes of Health, Bethesda, MD, USA).

Statistical analysis. All experiments in the present study were performed three times independently. Data are expressed as the mean \pm standard deviation and were analyzed using GraphPrism Prism 5.0 software (GraphPad Software, Inc., San Diego, CA, USA). An independent sample t-test was used for paired data significance calculation. Tukey's post hoc test was used to calculate the differences among groups. $\mathrm{P}<0.05$ was considered to indicate a statistically significant difference. 
Table I. Primers used for target amplification.

\begin{tabular}{lll}
\hline Primer & \multicolumn{1}{c}{ Forward (5'-3') } & \multicolumn{1}{c}{ Reverse (5'-3') } \\
\hline TM7SF4 & GTAAAACGACGGCCAGTTCGTCATCTTGGGACACGTAG & CTTTCTTTAGGAGTCGGCCAG \\
GADPH & TGTTGCCATCAATGACCCCTT & CTCCACGACGTACTCAGCG \\
PI3K & CACCGCATTTGTCGT & CTCCCACTTCTACGC \\
AKT & GTATGCTGGCAGAGTAGGAGAAC & CAGGTAACATCAGAGACAGACACA \\
mTOR & AGGCCGCATTGTCTCTATCAA & GCAGTAAATGCAGGTAGTCATCCA
\end{tabular}

TM7SF4, transmembrane 7 superfamily member 4; GADPH, glyceraldehyde 3-phosphate dehydrogenase; PI3K, phosphatidylinositol 3-kinase; mTOR, mammalian target of rapamycin.
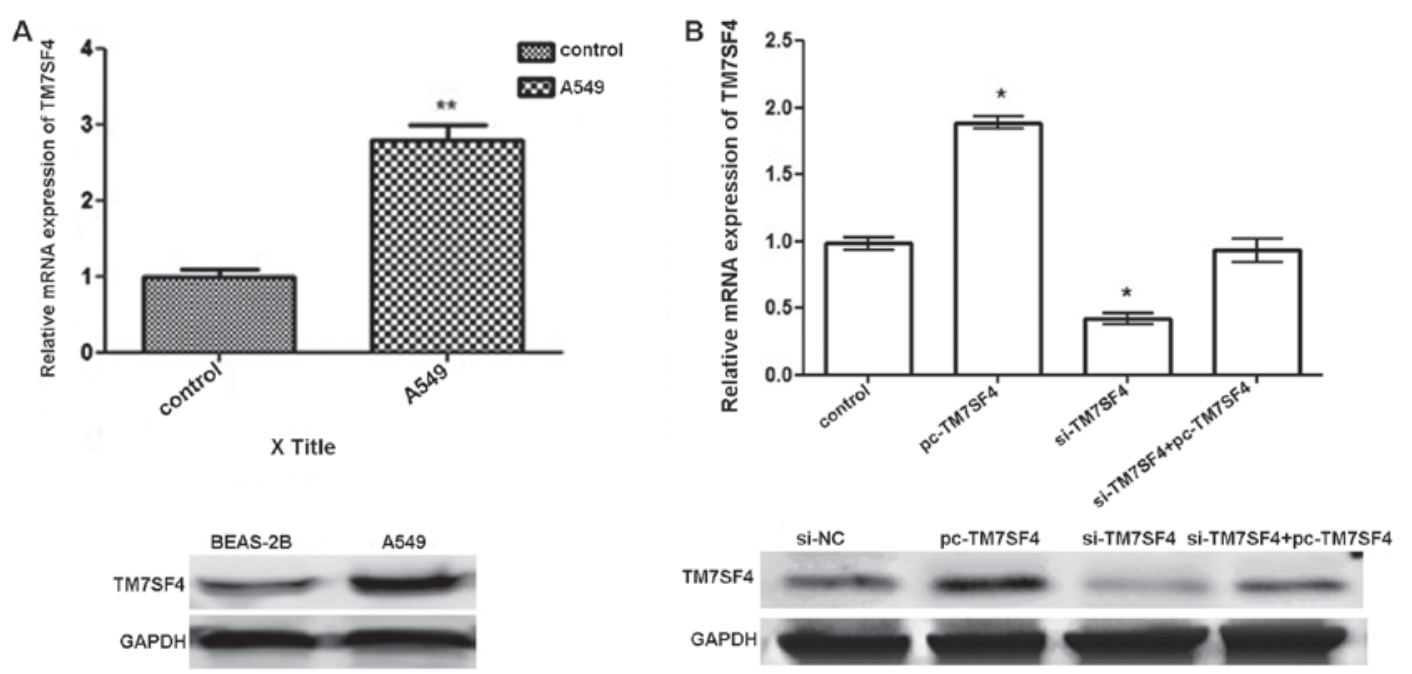

Figure 1. Expression of TM7SF4 in A549 cells. (A) RT-qPCR and western blot analyses revealed TM7SF4 was expressed at high levels in lung cancer cells. (B) pc-TM7SF4, si-TM7SF4, pc-TM7SF4+si-TM7SF4 were successfully transfected into A549 cells, and RT-qPCR and western blot analyses were performed to determine the mRNA and protein expression levels of TM7SF4. ${ }^{* * *} \mathrm{P}<0.01$ and ${ }^{*} \mathrm{P}<0.05$ vs. respective controls. TM7SF4, transmembrane 7 superfamily member 4; GADPH, glyceraldehyde 3-phosphate dehydrogenase; RT-qPCR, reverse transcription-quantitative polymerase chain reaction; si, small interfering RNA; NC, negative control.

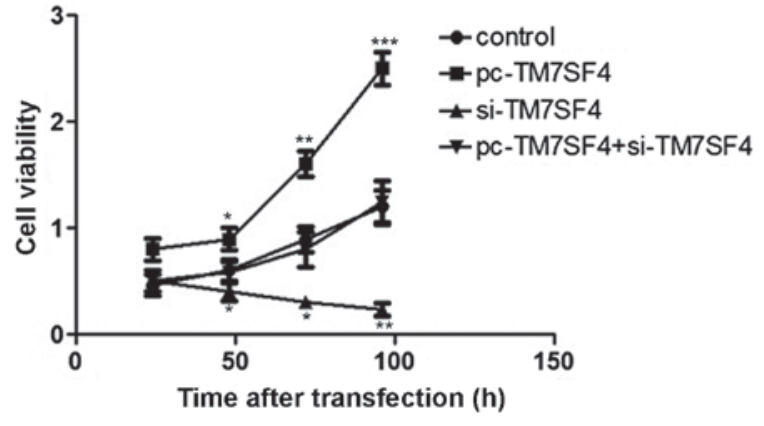

Figure 2. Effects of the expression of TM7SF4 on A549 cell proliferation. The cell viability of A549 cells transfected with si-TM7SF4, pc-TM7SF4 or si-TM7SF4+pc-TM7SF4 were detected following $25,50,75$ and $100 \mathrm{~h}$ of incubation. The suppression of TM7SF4 significantly downregulated the cell proliferation $(\mathrm{P}<0.01)$. TM7SF4, transmembrane 7 superfamily member 4 si, small interfering RNA. ${ }^{*} \mathrm{P}<0.05,{ }^{* *} \mathrm{P}<0.01$ and ${ }^{* * *} \mathrm{P}<0.001$ vs. respective controls.

\section{Results}

TM7SF4 expressed at high levels in lung cancer A549 cells. The results of the RT-qPCR analysis and western blot analysis revealed the expression of TM7SF4 at the mRNA level and protein level, respectively. As shown in Fig. 1A, the expression of TM7SF4 was significantly upregulated in the A549 cells, compared with the normal lung tissues and cell lines $(\mathrm{P}<0.01)$. As shown in Fig. 1B, the transfection with pc-TM7SF4 effectively upregulated the expression level of TM7SF4 in the A549 at the mRNA and protein levels. The transfection of cells with si-TM7SF4 successfully downregulated the expression level of TM7SF4 in the A549 cells.

Suppression of TM7SF4 inhibits cell proliferation. To determine the effect of the expression of TM7SF4 on A549 cell viability, an MTT assay was used to determine the proliferation rate of A549 cells following 25, 50, 75 and $100 \mathrm{~h}$ of transfection. The results showed that regulation of the expression of TM7SF4 stimulated the proliferation of A549 cells. The transfection of cells with si-TM7SF4 decreased A549 viability, compared with cells in the blank group ( $\mathrm{P}<0.01$; Fig. 2).

Suppression of TM7SF4 prevents A549 cell migration. In the subsequent experiments, A Transwell assay was used to examine the effects of TM7SF4 on A549 cell migration. The 
A

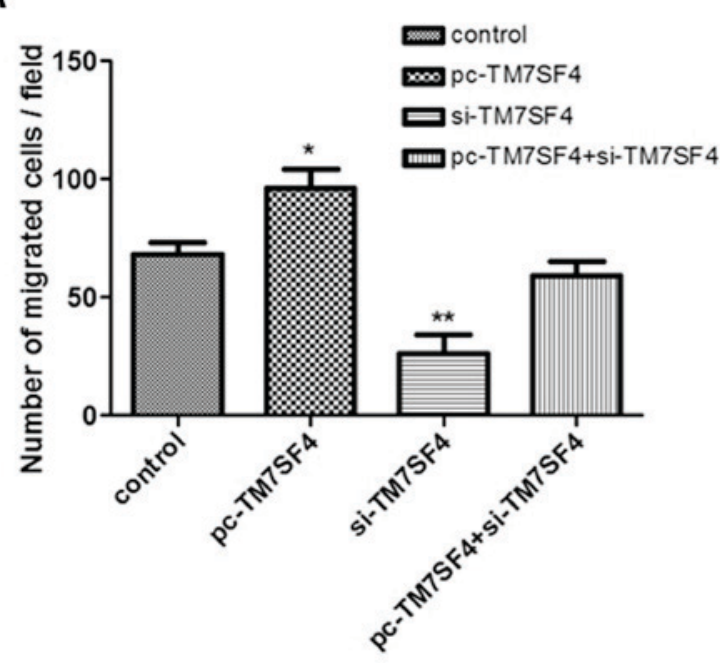

B

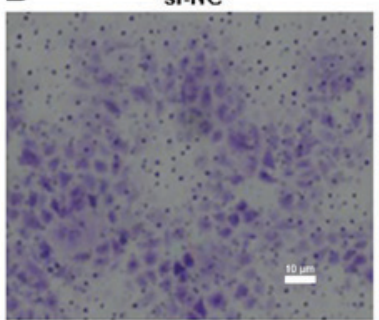

si-TM7SF 4

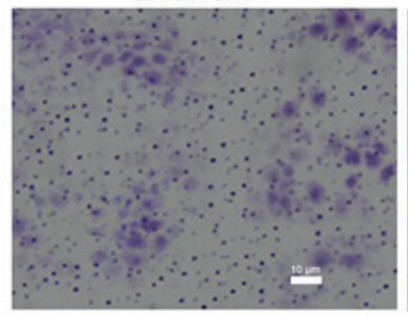

pc-TM7SF4

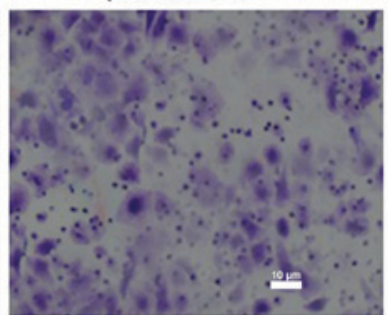

pc-TM7SF4+si-TM7SF 4

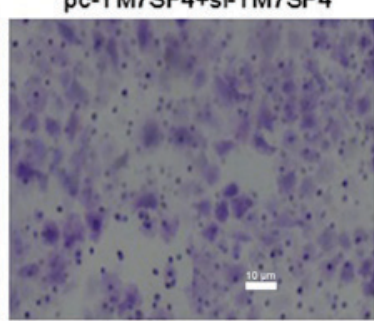

Figure 3. Effects of the expression of TM7SF4 on A549 cell migration. Transwell assays were performed to determine the effects of TM7SF4 on A549 cell migration. (A) In the si-TM7SF4 group, the inhibition of TM7SF4 significantly decreased cell migration (P<0.01) compared to that in the control, whereas the overexpression of TM7SF4 significantly $(\mathrm{P}<0.05)$ promoted cell migration compared to that in the control. (B) Images show staining for migration analysis. TM7SF4, transmembrane 7 superfamily member 4; si, small interfering RNA. ${ }^{*} \mathrm{P}<0.05$ and ${ }^{* *} \mathrm{P}<0.01$ vs. control. Scale bar $=10 \mu \mathrm{m}$.
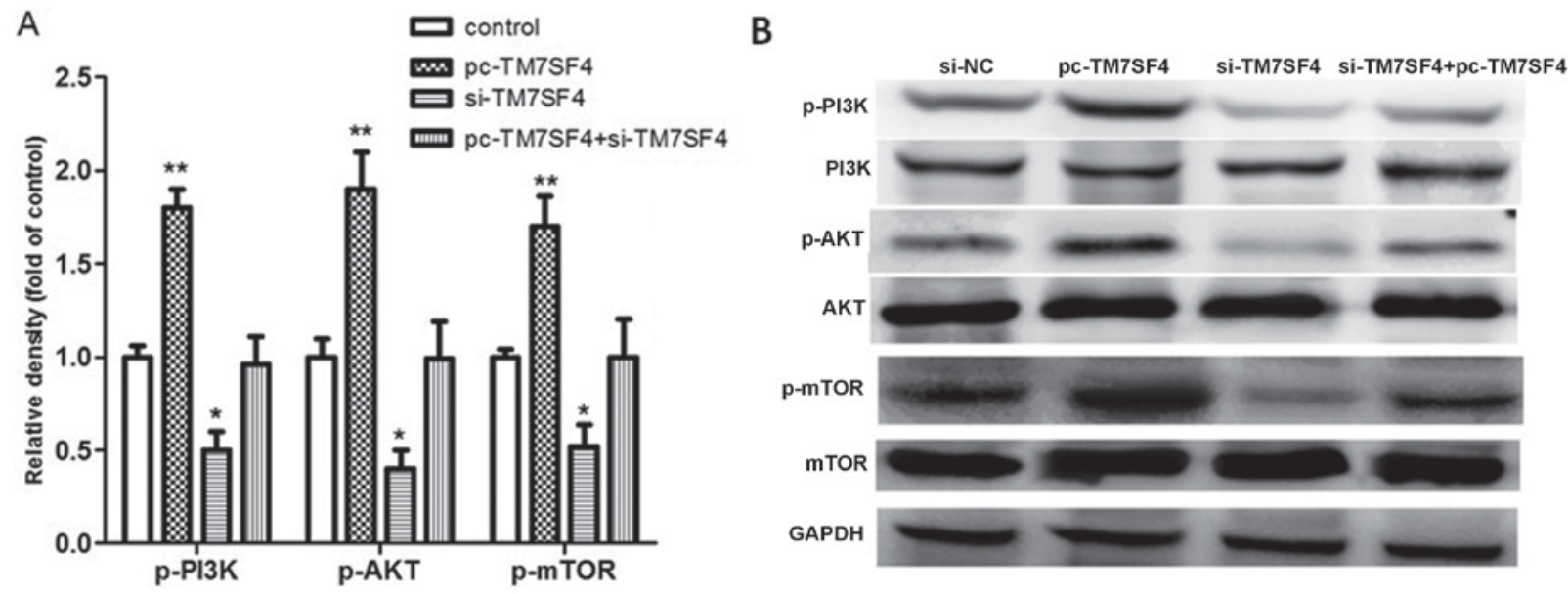

Figure 4. Signaling pathway evaluation using reverse transcription-quantitative polymerase chain reaction and western blot analyses. (A) Detection of relative densities of p-PI3K, p-AKT and p-mTOR in the si-TM7SF4, pc-TM7SF4 and si-TM7SF4+pc-TM7SF4 groups. (B) Western blot analysis of p-PI3K, PI3K, p-AKT, AKT, p-mTOR and mTOR. ${ }^{*} \mathrm{P}<0.05$ and ${ }^{* *} \mathrm{P}<0.01$ vs. control. TM7SF4, transmembrane 7 superfamily member 4; si, small interfering RNA; GADPH, glyceraldehyde 3-phosphate dehydrogenase; PI3K, phosphatidylinositol 3-kinase; mTOR, mammalian target of rapamycin; p-, phosphorylated; NC, negative control.

results, as shown in Fig. $3 \mathrm{~A}$ and $\mathrm{B}$, confirmed that the silencing of TM7SF4 significantly inhibited the migration ability of the A549 cells $(\mathrm{P}<0.01)$.

TM7SF4 regulates cell proliferation and migration by targeting the PI3K/AKT/mTOR pathway. To further determine the possible molecular mechanism underlying the effect of the abnormal expression of TM7SF4 on A549 cell biological processes, the expression levels of PI3K/AKT/mTOR signaling pathway-associated proteins were examined in the cells from each group. As shown in Fig. 4A, the overexpression of TM7SF4 increased the expression levels of p-PI3K, p-AKT and $\mathrm{p}$-mTOR $(\mathrm{P}<0.01)$, therefore, TM7SF4 may be associated with $\mathrm{p}-\mathrm{PI} 3 \mathrm{~K} / \mathrm{AKT}$ pathway activation. Subsequent experiments using western blot analysis were performed to examine the expression of associated proteins. The results, as shown in
Fig. 4B, confirmed that TM7SF4 regulated cell migration and invasion through the p-PI3K/AKT pathway.

\section{Discussion}

Lung cancer is one of the leading causes of mortality without an effective treatment strategy, the prevalence and mortality rates of which continue to increase rapidly worldwide $(17,18)$. As a result, it is important to elucidate the molecular mechanisms underlying the promotion of cell proliferation, migration and signaling pathways in lung cancer cells for elucidation of treatments and therapeutic strategies.

TM7SF4 encodes a seven-pass transmembrane protein, and this protein regulates immunological functions, osteoclastogenesis and myeloid differentiation (19). TM7SF4 has been reported be important in Paget's disease of bone, papillary 
thyroid cancer and breast cancer, however, the association between TM7SF4 and lung cancer has not been reported $(6,20)$. The present study investigated the expression of TM7SF4 in lung cancer and provided the first confirmation, to the best of our knowledge, that TM7SF4 was expressed at a high level in lung cancer cells, determined using RT-qPCR analysis.

The present study examined the association between TM7SF4 and cell viability, and migration. TM7SF4 was found to promote the viability and migration of the A549 cells, therefore, the possibly pathways were subsequently investigated.

Alterations of signaling pathways are important in the regulation of multiple cellular functions of lung cancer, including cell growth and proliferation (21-24). A previous study by Zhu et al confirmed that the AKT signaling pathway is involved in the intrinsic apoptosis of non small-cell lung cancer cells (25). In another report, microRNA-223 was identified as a potential therapeutic target for overcoming epidermal growth factor receptor-tyrosine kinase inhibitor resistance, owing to its function in inducing activation of the PI3K/AKT/mTOR signaling pathway in PC9/ER and PC9/CD133+ cells, which is responsible for the resistance of PC9/ER and PC9/CD133+ cells to erlotinib (26). Additionally, a study by Wan et al suggested that insufficient RFA activates tumor growth in vitro and in vivo via PI3K/AKT/mTOR signals (27).

In the present study, the AKT signaling pathway in lung cancer cells was investigated. Using the method of gene silencing, it was found that silencing TM7SF4 inhibited the proliferation and metastasis of lung cancer through regulating activation of the PI3K/AKT/mTOR signaling pathways. In particular, the results showed that the expression levels of p-PI3K, p-AKT and p-mTOR were activated when TM7SF4 was overexpressed, whereas the inhibition of TM7SF4 inhibited this response. Therefore, TM7SF4 was found to be important in the proliferation and metastasis of lung cancer. Taken together, the present study confirmed that TM7SF4 was upregulated in A549 lung cancer cells, and that the downregulation of TM7SF4 may have certain suppressive roles in the development and metastasis of lung cancer through suppressing activation of the PI3K/AKT/mTOR signaling pathway. These findings confirmed that TM7SF4 may be closely involved in the progression and development of lung cancer, and may be a novel therapeutic target for this disease. Insufficient mechanistic understanding has hindered the prognosis of lung cancer, however, the present study indicated a novel potential therapeutic approach to improve success in treating lung cancer via targeting the identified PIKT/AKT/mTOR signaling pathway. The present study provides a foundation for further elucidation of the role of TM7SF4 in lung cancer. Specific elements of the underlying mechanism require further validation experiments.

\section{Acknowledgements}

This study was supported by the Natural Science Foundation of Shandong Province, China (grant no. 2009ZRB14066).

\section{References}

1. D'Addario G, Früh M, Reck M, Baumann P, Klepetko W and Felip E; ESMO Guidelines Working Group: Metastatic non-small-cell lung cancer: ESMO clinical practice guidelines for diagnosis, treatment and follow-up. Ann Oncol 21 (Suppl 5): v116-v119, 2010.
2. Ferlay J, Steliarova-Foucher E, Lortet-Tieulent J, Rosso S, Coebergh JW, Comber H, Forman D and Bray F: Cancer incidence and mortality patterns in Europe: Estimates for 40 countries in 2012. Eur J Cancer 49: 1374-1403, 2013.

3. Sherwood JL, Corcoran C, Brown H, Sharpe AD, Musilova M and Kohlmann A: Optimised pre-analytical methods improve KRAS mutation detection in circulating tumour DNA (ctDNA) from patients with non-small cell lung cancer (NSCLC). PLoS One 11: e0150197, 2016.

4. Quéré G, Descourt R, Robinet G, Autret S, Raguenes O, Fercot B, Alemany P, Uguen A, Férec C, Quintin-Roué I and Le Gac G: Mutational status of synchronous and metachronous tumor samples in patients with metastatic non-small-cell lung cancer. BMC Cancer 16: 210, 2016.

5. Zequn N, Xuemei Z, Wei L, Zongjuan M, Yujie Z, Yanli H, Yuping Z, Xia M, Wei W, Wenjing D, et al: The role and potential mechanisms of LncRNA-TATDN1 on metastasis and invasion of non-small cell lung cancer. Oncotarget 7: 18219-18228, 2016.

6. Donáth J, Speer G, Kósa JP, Árvai K, Balla B, Juhász P, Lakatos P and Poór G: Polymorphisms of CSF1 and TM7SF4 genes in a case of mild juvenile Paget's disease found using next-generation sequencing. Croat Med J 56: 145-151, 2015.

7. Chung PY, Beyens G, de Freitas F, Boonen S, Geusens P, Vanhoenacker F, Verbruggen L, Van Offel J, Goemaere S, Zmierczak HG, et al: Indications for a genetic association of a VCP polymorphism with the pathogenesis of sporadic Paget's disease of bone, but not for TNFSF11 (RANKL) and IL-6 polymorphisms. Mol Genet Metab 103: 287-292, 2011.

8. Valerio MS, Herbert BA, Griffin AC III, Wan Z, Hill EG and Kirkwood KL: MKP-1 signaling events are required for early osteoclastogenesis in lineage defined progenitor populations by disrupting RANKL-induced NFATc1 nuclear translocation. Bone 60: 16-25, 2014.

9. Safdari Y, Khalili M, Ebrahimzadeh MA, Yazdani Y and Farajnia S: Natural inhibitors of PI3K/AKT signaling in breast cancer: Emphasis on newly-discovered molecular mechanisms of action. Pharmacol Res 93: 1-10, 2015.

10. Ye Y, Tang X, Sun Z and Chen S: Upregulated WDR26 serves as a scaffold to coordinate PI3K/AKT pathway-driven breast cancer cell growth, migration, and invasion. Oncotarget 7: 17854-17869, 2016.

11. McAuliffe PF, Meric-Bernstam F, Mills GB and Gonzalez-Angulo AM: Deciphering the Role of PI3K/Akt/mTOR pathway in breast cancer biology and pathogenesis. Clin Breast Cancer 10 (Suppl 3): S59-S65, 2010.

12. Fu J, Lv H, Guan H, Ma X, Ji M, He N, Shi B and Hou P: Metallothionein $1 \mathrm{G}$ functions as a tumor suppressor in thyroid cancer through modulating the PI3K/Akt signaling pathway. BMC Cancer 13: 462, 2013.

13. Fumarola C, Bonelli MA, Petronini PG and Alfieri RR: Targeting PI3K/AKT/mTOR pathway in non small cell lung cancer. Biochemical Pharmacol 90: 197-207, 2014.

14. Lu L, Li C, Li D, Wang Y, Zhou C, Shao W, Peng J, You Y, Zhang $\mathrm{X}$ and Shen X: Cryptotanshinone inhibits human glioma cell proliferation by suppressing STAT3 signaling. Mol Cell Biochem 381: 273-282, 2013.

15. Livak KJ and Schmittgen TD: Analysis of relative gene expression data using real-time quantitative PCR and the 2(-Delta Delta C(T)) method. Methods 25: 402-408, 2001.

16. Nam KS, Oh S, Lee KM, Yoo SA and Shin I: CD44 regulates cell proliferation, migration, and invasion via modulation of c-Src transcription in human breast cancer cells. Cell Signal 27: 1882-1894, 2015

17. Imogen L and Gillham CM: Chemotherapy for lung cancer. N Engl J Med 346: 1498, 2002.

18. Shaw AT, Ou SH, Bang YJ, Camidge DR, Solomon BJ, Salgia R, Riely GJ, Varella-Garcia M, Shapiro GI, Costa DB, et al: Crizotinib in ROS1-rearranged non-small-cell lung cancer. N Engl J Med 372: 1963-1971, 2014.

19. Chung PY, Beyens G, Boonen S, Papapoulos S, Geusens P, Karperien M, Vanhoenacker F, Verbruggen L, Fransen E, Van Offel J, et al: The majority of the genetic risk for Paget's disease of bone is explained by genetic variants close to the CSF1, OPTN, TM7SF4, and TNFRSF11A genes. Hum Genet 128: 615-626, 2010.

20. Albagha OM, Wani S and Ralston SH: Identification of a functional variant in the TM7SF4 gene that is associated with susceptibility to Paget's disease of bone. Bone 48: S88, 2011. 
21. Mino-Kenudson M and Mark EJ: Reflex testing for epidermal growth factor receptor mutation and anaplastic lymphoma kinase fluorescence in situ hybridization in non-small cell lung cancer. Arch Pathol Lab Med 135: 655-664, 2011.

22. Feng N, Luo J and Guo X: Silybin suppresses cell proliferation and induces apoptosis of multiple myeloma cells via the PI3K/Akt/mTOR signaling pathway. Mol Med Rep 13: 3243-3248, 2016.

23. Zhang G, Wang C, Sun M, Li J, Wang B, Jin C, Hua P, Song G, Zhang Y, Nguyen LL, et al: Cinobufagin inhibits tumor growth by inducing intrinsic apoptosis through AKT signaling pathway in human nonsmall cell lung cancer cells. Oncotarget 7: 28935-28946, 2016

24. Zhao XZ, Liu Y, Zhou LJ, Wang ZQ, Wu ZH and Yang XY: Role of estrogen in lung cancer based on the estrogen receptor-epithelial mesenchymal transduction signaling pathways. Onco Targets Ther 8: 2849-2863, 2015.
25. Zhu Q, Liang X, Dai J and Guan X: Prostaglandin transporter, SLCO2A1, mediates the invasion and apoptosis of lung cancer cells via PI3K/AKT/mTOR pathway. Int J Clin Exp Pathol 8: 9175-9181, 2015.

26. Hu J, Boeri M, Sozzi G, Liu D, Marchianò A, Roz L, Pelosi G, Gatter K, Pastorino U and Pezzella F: Gene signatures stratify computed tomography screening detected lung cancer in high-risk populations. Ebiomedicine 2: 829-840, 2015.

27. Wan J, Wu W, Chen Y, Kang N and Zhang R: Insufficient radiofrequency ablation promotes the growth of non-small cell lung cancer cells through PI3K/Akt/HIF-1 $\alpha$ signals. Acta Biochim Biophys Sin (Shanghai) 48: 371-377, 2016. 